УДК 323.14

Пётр ОСКОЛКОВ

\title{
К ВОПРОСУ ОБ ЭТНОПОЛИТИЧЕСКОЙ ДИНАМИКЕ ЕВРОПЫ
}

\begin{abstract}
Аннотация. Этнополитология - одна из наиболее динамично развивающихся областей политической науки, её важность и актуальность для мирового развития трудно переоценить. В России этнополитологическая традиция, несмотря на молодость, достаточно развита и признана. Обращает на себя внимание появление новых фундаментальных отечественных работ, посвящённых этнополитическим процессам. Автор статьи обращается к новой книге А.И. Тэвдой-Бурмули “Этнополитическая динамика Европейского союза”, опубликованной в 2018 г. издательством “Аспект-Пресс". Это учебное пособие с грифом ФУМО по укрупнённой группе специальностей и направлений подготовки 41.00.00 "Политические науки и регионоведение", состоящее из общетеоретической главы и глав, структурированных в соответствии с географическим (Западная Европа и ЦВЕ) и масштабным (национализм меньшинств и государствообразующего этноса, а также взаимодействие национализма с наднациональными проектами) принципами. В работе, написанной преимущественно в конструктивистском ключе, содержатся авторские трактовки происходящих в Европе этнополитических взаимодействий, разрабатывается ряд оригинальных аналитических и объяснительных теорий. Особое внимание уделяется специфике этнополитического регулирования и субъект-объектным отношениям в сфере этнического. При этом автор пособия не позиционирует себя в отрыве от мирового этнополитологического контекста, опираясь на ведущие теоретические и эмпирические исследования, предпринятые в последние годы европейскими и американскими коллегами. В ситуации “концептуальной трясины”, царящей, по выражению академика РАН В.А. Тишкова, в отечественной этнополитологии, появление подобной книги - событие для экспертного и образовательного сообщества.

Ключевые слова: этнополитология, этнополитическая динамика, этнополитика, национализм, конструктивизм, Европейский союз, мультикультурализм.
\end{abstract}

Этнополитология в России, как и в мире, - относительно молодая отрасль научного знания. Один из учёных, стоявших у истоков отечественной этнополитологии, В.А. Тишков, даже экспрессивно назвал её “жертвой аборта”, возникшей в результате “поисков после разрушения советской номенклатуры общественных наук” [Этнополитология сегодня..., 2011: 264]. Выбор учебных пособий, посвящённых этнополитической

(C) Осколков Пётр Викторович - м.н.с., отдел исследований европейской интеграции Института Европы РАН, преподаватель, кафедра сравнительной политологии МГИМО МИД России; ст. преподаватель, кафедра региональных проблем мировой политики МГУ им. М.В. Ломоносова. Адрес: 125009, Россия, Москва, ул. Моховая, д. 11-3. E-mail: p.oskolkov@inno.mgimo.ru

DOI: http://dx.doi.org/10.15211/soveurope62018152158 
проблематике, невелик, и все они имеют те или иные недостатки. Поэтому учебное пособие А.И. Тэвдой-Бурмули “Этнополитическая динамика Европейского Союза” по многим критериям представляет собой весьма ценный вклад в российскую политическую науку.

Книга представляет собой результаты исследования европейской этнополитической динамики как производной от национализма государствообразующих и миноритарных этносов, деятельности институционализированных и неинституционазированных акторов. А.И. Тэвдой-Бурмули рассматривает различные факторы, влияющие на то или иное развитие этнополитической ситуации, сравнивает ситуацию в Западной Европе и ЦВЕ и делает выводы относительно взаимосвязи этнополитической динамики и развития европейской интеграции. Исходя из вышесказанного, данную книгу можно было бы смело классифицировать как монографию, поскольку в ней представлены совершенно оригинальные концепции; однако поскольку “Этнополитическая динамика Европейского Союза” заявлена и оформлена автором как учебное пособие и даже получила в таком качестве гриф ФУМО по укрупнённой группе специальностей и направлений подготовки 41.00.00 “Политические науки и регионоведение”, будем считать её таковым.

Упомянутый выше В.А. Тишков охарактеризовал состояние дел в этнополитической терминологии как “ситуацию концептуальной трясины” [Тишков, 2010: 196]. В этом смысле надо отдать должное А.И. Тэвдой-Бурмули, снабдившему своё учебное пособие теоретической главой, в которой концептуализируются основные понятия дисциплины; таким образом, к последующим, более конкретным главам читатель подходит, уже вооружившись соответствующим инструментарием.

Здесь необходимо упомянуть парадигму, в рамках которой написана работа. В основе практически любого этнополитического конструкта в настоящее время лежит понятие этничности, и понятие это является камнем преткновения для исследователей. Существуют два основных подхода к пониманию этничности: эссенциалистский, или примордиалистский (от primo ordo - “первоочередной”), и конструктивистский. Отдельные этнополитологи выделяют также функционалистский и инструментальный подход [Тишков, Шабаев, 2011: 37], но, на наш взгляд, они представляют собой вариации на тему конструктивизма (хотя инструментализм, возможно, и стоит отличать от конструктивизма в силу акцента, который его сторонники - Дж. Ротшильд, Т. Эриксен и др. - делают на целеполагании, то есть активном начале, присущем объекту этнических процессов, в зависимости от инструментальной необходимости избирающему ту или иную этничность; всё же большинство конструктивистов не придают объекту субъектных характеристик, полностью приписывая конструирующие этничность свойства естественно сложившейся социальной организации).

Сторонники эссенциалистского подхода мыслят этничность как нечто, объективно и априорно существующее (хотя и в последние десятилетия не в биологическом, а в культурном смысле), приверженцы же конструктивизма считают, что этническая идентичность есть социально конструируемая (как индивидом, так и группой, и государством) и поддающаяся изменениям сфера реальности. Соответственно все учебные пособия и монографии, посвящённые изучению этнических аспектов политики, исходят из эссенциалистской (работы Р.Г. Абдулатипова, Э. Смита, К. Гирца, в определённой мере М.Х. Фарукшина) либо конструктивистской (труды В.А. Тишкова, Ю.П. Шабаева, А.П. Садохина, Э. Геллнера, Б. Андерсона, Р. Брубейкера) точки зрения. В этом смысле А.И. Тэвдой-Бурмули предстаёт скорее сторонником конструктивистского подхода, что, безусловно, повлияло на авторскую трактовку категориального аппарата дисциплины.

А.И. Тэвдой-Бурмули рассматривает этничность, как, собственно, следует из названия книги, как некий динамический процесс, способный “просыпаться, консолидироваться и погружаться в сон" [Тэвдой-Бурмули, 2018: 16], а нацию - как политическую Современная Европа, 2018, №6 
актуализацию данного процесса. Автор указывает на распространённую среди некоторых исследователей ошибку: классификацию любых этнических взаимодействий как этнополитических. Дабы избежать подобной аберрации, А.И. Тэвдой-Бурмули предлагает трактовать некое взаимодействие как этнополитическое только в случае наличия в нём двух факторов: этнической самоидентификации в мотивации политических амбиций группы-субъекта и воздействия на параметры этнической идентичности группыобъекта. С нашей точки зрения, однако, некритическое применение данных ограничений может привести, напротив, к чрезмерно эксклюзивному толкованию этнополитических взаимодействий; необходимо разъяснить, что воздействие на параметры этнической идентичности объекта может и должно пониматься максимально широко.

Авторское определение национализма достаточно оригинально и обладает многими преимуществами перед более узкими или же более широкими определениями, данными ранее другими исследователями. Если В.С. Малахов и Дж. Бройи помещают национализм в контекст суверенитета, Э. Геллнер увязывает его с территорией, а Э. Смит говорит об “автономности и единстве” нации, то А.И. Тэвдой-Бурмули рассматривает национализм прежде всего с точки зрения социальной психологии и лояльности, определяя его как “активную лояльность индивида к культурной общности, с которой его в данный момент времени связывают самые прочные идентитарные узы” [ТэвдойБурмули, 2018: 22]. Подобное определение подразумевает гибкость и изменчивость объекта националистической лояльности, что подтверждается многими практическими примерами. Также важен взгляд автора на национализм как на "один из существующих принципов структурирования политического пространства” [Тэвдой-Бурмули, 2018: 156]; в рамках подобного взгляда национализм перерастает рамки идеологии и приобретает черты мировоззрения, каковым в большинстве случаев и является (здесь уместно вспомнить Х. Кона, писавшего, что “национализм - это состояние ума, согласно которому высшая лояльность индивида принадлежит национальному государству” [Kohn, 1965: 9]).

Национализм неизбежно связан с политической культурой; А.И. Тэвдой-Бурмули достаточно подробно рассматривает эту связь, определяя политическую культуру как “совокупность элементов политического поведения, характерных для данной группы и основанных на определённых ценностных ориентациях и стереотипах восприятия реально существующего и значимого для этой группы политического процесса" [ТэвдойБурмули, 2018: 145]. Подобное определение отличается от большинства существующих прежде всего акцентом на политическое поведение, в котором, собственно говоря, политическая культура и проявляется. Автор даже считает возможным говорить о “националистическом типе политической культуры”, для которого характерно превращение образования и культуры в элементы политического выбора.

М.А. Деркач отмечает многообразие терминов, используемых для обозначения современных партий, эксплуатирующих дискурс мобилизованной этничности: среди вариантов эпитетов, которыми награждают данные партии, отечественный автор перечисляет radical right, extreme right, right-wing extremist, extreme right-wing, populist radical right, right-wing populist, radical right-wing, anti-system, anti-immigrant, “крайне правые", “крайне правые популистские", "праворадикальные" и "националистические" [Деркач, 2017: 7-8]; мы могли бы добавить к этому списку “правоэкстремисткие” и “правопопулистские”. В условиях подобного многоцветья большое значение для понимания институционализированных этнополитических процессов имеет предпринятое А.И. Тэвдой-Бурмули концептуальное разделение радикализма и экстремизма (в силу присущей последнему антисистемности), а также радикализма и популизма на основе “разной степени привязки к оси политических предпочтений” [Тэвдой-Бурмули, 2018:

Современная Европа, 2018, №6 
36] (центристский популизм возможен, центристский радикализм едва ли) и большей склонности радикализма к “продуцированию авторитарного дискурса" (впрочем, здесь автор вступает в противоречие с известным нидерландским и американским теоретиком правого популизма К. Мюдде, называющим авторитарность одним из ключевых отличительных признаков именно правых популистов) [Mudde, 2010: 1173-1175].

Не ускользают от взгляда исследователя и различные практики инкорпорации иноэтничных мигрантов. Особое внимание в книге уделяется мультикультурализму; соответствующий параграф служит хорошим дополнением к увидевшей свет летом 2018 г. монографии А.В. Веретевской [Веретевская, 2018]. А.И. Тэвдой-Бурмули обращает внимание на постепенное обесценивание изначального смысла мультикультурного концепта, так как, по его словам, в настоящее время мультикультурным считается любое общество, не практикующее очевидной ассимиляции. Мультикультурализм, по мнению автора, обязан своим успехом соответствием постмодернистским философским подходам к этнополитическому менеджменту, этическим аспектам постколониального мироустройства и переходу ЕС и НАТО к ценностно-ориентированной политике. Однако сторонникам реализации политики мультикультурализма часто не удаётся избежать ряда ловушек: во-первых, имеется определённое противоречие между мультикультуралистским предпочтением групповых, социокультурных прав и либеральным принципом правового индивидуализма; во-вторых, политика мультикультурализма, будучи направленной на сохранение и культивирование этнической самоидентификации, может вести к архаизации национальной идентичности и тесно связанному с ней феномену расщепления идентичности политической и социокультурной.

Польский социолог П. Штомпка разделял теории на объяснительные, аналитические, эвристические и экзегетические [Штомпка, 2005]. А.И. Тэвдой-Бурмули предлагает ряд аналитических и объяснительных теорий, которые в перспективе могут иметь большое значение для этнополитологии. К наиболее существенным аналитическим новациям автора обсуждаемой книги относится, к примеру, периодизация послевоенной националистической активности государствообразующих этносов Западной Европы в соответствии с тремя параметрами: доминирующим фактором активизации национализма, доминирующей идеологией и доминирующими организационными формами националистического движения. На первом этапе (1940-1960-е гг.) националистические эмоции определялись модернизацией и деколонизацией с преобладанием в политическом поле маргинальных групп и партий-однодневок, на втором, транзитном этапе (1960-1970-е гг.) правонационалистические движения получают разработанную идеологическую базу в виде наследия идейно-философской школы “новых правых" и возрастает значение иммиграционного фактора, третий этап охарактеризовался формированием успешных правопопулистских партий, инфильтрацией их риторики в дискурс истеблишмента и интенсификацией интеграционного процесса. Применительно к ЦВЕ автор добавляет к временному пространственный аспект, выделяя три зоны этнополитической активности: “Османское наследие” (Балканские страны), “Травмированная сложившаяся государственность” (Польша и Венгрия) и “Молодая нация" (характерные примеры - Латвия и Эстония). Движения коренных этнических меньшинств А.И. Тэвдой-Бурмули предлагает классифицировать на основе критериев мотивации движения, характера выдвигаемых требований (с нашей точки зрения, эти два параметра можно было бы объединить в один в целях упрощения категориальной схемы), а также системности движения и степени децентрализации регионального управления.

Объяснительную ценность несут многие выводы, сделанные А.И. Тэвдой-Бурмули относительно причинно-следственных связей в развитии националистических движений разных типов. Говоря об этнополитической активности коренных этнических Современная Европа, 2018, №6 
меньшинств в странах ЕС, автор выделяет такие факторы, как структурный кризис, вызванный внутригосударственной модернизацией (в форме ранней индустриализации, распада аграрной экономики и т.д.), эволюция статуса региона проживания данных меньшинств (и - шире - в целом эволюция модели взаимоотношений центр - регионы). Националистическим движениям меньшинства присущи неизбежная эволюция от организации неэлекторального типа к организации электоральной (примером являются многочисленные сепаратистские и ирредентистские движения Западной и Южной Европы, рано или поздно начинающие принимать участие в электоральной политике), а также перманентная конкуренция (радикально-)идеологической и политической мотиваций поведения, партийным и непартийным образом действий (здесь уместно вспомнить раскол баскской ЭТА на ETA militar и ETA político-militar). При этом автор утверждает, что "интенсивность использования языка и культуры в пропагандистских целях тем выше, чем отчётливее выражен в данном региональном социуме этнокультурный критерий самоидентификации и чем уже круг альтернативных, годных для целей националистической мобилизации сюжетов" [Тэвдой-Бурмули, 2018: 205] - имеются в виду в том числе экономические основания. С последним заявлением мы склонны согласиться лишь отчасти, так как подобная точка зрения, доведённая до максимума, предполагает обращение к этнокультурной идентичности по остаточному принципу, в случае если нет других оснований для мобилизации. Однако мы считаем возможным рассматривать этнокультурные основания как базовые, в наибольшей степени способные апеллировать к эмоционально-психологической составляющей политического поведения, а следовательно, задействование данных оснований наиболее эффективно во всех случаях, в том числе там, где круг “альтернативных сюжетов” достаточно широк.

Интересны и тезисы автора о заимствовании правыми радикалами правозащитного дискурса (представление себя жертвами произвола) и о “синдроме кукушки” (захвате политической сцены маргинальным актором - А.И. Тэвдой-Бурмули приводит данный термин в контексте фламандской политики; нам представляется возможным включить в данный кластер также, как минимум, Австрийскую партию свободы и Датскую народную партию), а также о противоречии между двумя подходами к панъевропейской идее - на базе культурно-цивилизационной либо гражданской политикотерриториальной идентичности - как одной из наиболее существенных причин евроскептицизма. Рассматривая ситуацию в ЦВЕ, автор уделяет внимание, в том числе, этнополитике в странах Балтии, объясняя феномен “негражданства" социокультурной фрустрацией эстонского и латвийского социумов после пребывания в составе СССР, характером новой элиты, дополненной эмигрантскими элементами, а также спецификой kin-state русскоязычного меньшинства (в терминах Р. Брубейкера).

Несмотря на многочисленные новации, нельзя сказать, что авторская мысль парит в отрыве от мирового этнополитологического контекста: так, в определяющей структуру книги типологии национализма по типу носителя (национализм государствообразующей группы, национализм этнического меньшинства и наднациональный национализм) можно заметить косвенную отсылку к типологии Ч. Тилли, который предложил дихотомию state-led nationalism (“правители, которые говорят от имени нации, успешно требуют от подданных, чтобы они идентифицировали себя с этой нацией и подчиняли все другие интересы интересам государства") и state-seeking nationalism (“представители части населения, в настоящий момент не осуществляющей коллективный контроль над государством, требуют автономного политического статуса или даже отдельного государства на основании особой культурной идентичности") [Tilly, 1994: 133]. Работа снабжена внушительным списком литературы на четырёх языках и опирается на ведущие разработки отечественных и зарубежных учёных. 
Не пытаясь объять необъятное, А.И. Тэвдой-Бурмули не рассматривает по отдельности каждую страну Европейского Союза, но, говоря о том или ином субрегионе (в фокусе исследователя оказались Западная Европа и ЦВЕ), приводит эмпирические данные по "модельным" странам: в случае Западной Европы это Германия, Австрия, Франция, Великобритания, Бельгия, в Центральной и Восточной Европе - Польша, Венгрия, Чехия и страны Балтии. Для формата учебного пособия этого более чем достаточно, а в случае необходимости получения дополнительной эмпирической верификации авторских концепций читатель без труда может найти требуемую информацию на новостных порталах соответствующих стран.

Конечно, не все положения "Этнополитической динамики Европейского Союза" бесспорны. Если политологи-примордиалисты “споткнутся” уже о конструктивистское определение национализма, то некоторые институционалисты могли бы поспорить с концептуализацией радикальных и экстремистских партий, а ряд историков - не согласиться с идеей о модернизации как стимуле национализма меньшинств, вспомнив вслед за Дж. Бройи пример Османской империи, именно упадок и архаизация которой привели к возникновению мощных националистических движений на Балканах [Бройи, 2002: 229-230]. Однако в способности провоцировать дискуссии заключается одно из достоинств любой научной работы.

Подводя итог этому краткому обзору, можно сказать с уверенностью, что оригинальные авторские концепции вносят существенный вклад в политическую науку, а “Этнополитической динамике Европейского Союза" уготована судьба одной из базовых работ для российской этнополитологии. Причём интерес она представляет как для исследователей, в фокусе внимания которых находятся западно- и восточноевропейские сюжеты, так и благодаря широкой концептуальной рамке для специалистов по российской и азиатской этнополитической проблематике. Также, будучи снабжена поглавными списками обязательной и дополнительной литературы и маркирована грифом ФУМО, книга, несомненно, найдёт своё место в учебных программах для студентовполитологов.

\section{Список литературы}

Бройи Дж. (2002) Подходы к исследованию национализма // Наџии и наџионализм. М.: Праксис. C. 201-235.

Веретевская А.В. (2018) Мультикультурализм, которого не было: анализ европейских практик политической интеграции этнокультурных меньшинств. М.: МГИМО МИД России. $182 \mathrm{c}$.

Деркач М.А. (2017) История популистских партий в Швеции и Финляндии в 2006-2015 гг. : дис. ... канд. ист. наук : 07.00 .03 / науч. рук. Г.М. Михалёва; РГГУ. Москва. 266 с.

Тишков В.А. (2010) Постнационалистическое понимание национализма? // Национализм 8 поздне- и посткоммунистической Европе. М.: РОССПЭН. С. 196-227.

Тишков В.А., Шабаев Ю.П. (2011) Этнополитология: политические функции этничности. М.: Издательство Московского университета. 376 с.

Тэвдой-Бурмули А.И. (2018) Этнополитическая динамика Европейского Союза. М.: АспектПресс. 224 c.

Штомпка П. (2005) Формирование социологического воображения. Значение теории. Социологические исследования. № 10. С. 64-72.

Этнополитология сегодня: интервью в.н.с. ИНИОН РАН О.Ю. Малиновой с академиком РАН, директором Института этнологии и антропологии РАН им. Н.Н. Миклухо-Маклая и Центра социальной антропологии РГГУ В.А. Тишковым (2011) // Политическая наука. № 1. С. 264-276.

Kohn H. (1965) Nationalism: Its Meaning and History. Malabar: Robert E. Krieger Publishing Company. $191 \mathrm{p}$.

Mudde C. (2010) The Populist Radical Right: A Pathological Normalcy // West European Politics. Vol. 33. No. 6. P. 1173-1175.

Современная Европа, 2018, №6 
Tilly Ch. (1994) States and Nationalism in Europe 1492-1992 // Theory and Society. Vol. 23. No. 1. P. $131-146$.

\section{References}

Breuilly G. (2002) Podhody k issledovaniju nacionalizma // Nacii i nacionalizm. M.: Praksis. Pp. 201-235.

Derkach M.A. (2017) Istorija populistskih partij v Shvecii i Finljandii v 2006-2015 gg. : PhD thesis in History: 07.00.03 / advisor G.M. Mihaljova; RGGU. Moskva. 266 p.

Jetnopolitologija segodnja: interv'ju v.n.s. INION RAN O.Ju. Malinovoj s akademikom RAN, direktorom Instituta jetnologii i antropologii RAN im. N.N. Mikluho-Maklaja i Centra social'noj antropologii RGGU V.A. Tishkovym (2011) // Politicheskaja nauka. № 1. P. 264-276.

Kohn H. (1965) Nationalism: Its Meaning and History. Malabar: Robert E. Krieger Publishing Company. $191 \mathrm{p}$.

Mudde C. (2010) The Populist Radical Right: A Pathological Normalcy // West European Politics. Vol. 33. No. 6. P. 1173-1175.

Sztompka P. (2005) Formirovanie sociologicheskogo voobrazhenija. Znachenie teorii. Sociologicheskie issledovanija. № 10. P. 64-72.

Tilly Ch. (1994) States and Nationalism in Europe 1492-1992 // Theory and Society. Vol. 23. No. 1. P. $131-146$.

Tishkov V.A. (2010) Postnacionalisticheskoe ponimanie nacionalizma? // Nacionalizm v pozdne- $i$ postkommunisticheskoj Evrope. M.: ROSSPJeN. P. 196-227.

Tishkov V.A., Shabaev Ju.P. (2011) Jetnopolitologija: politicheskie funkcii jetnichnosti. M.: Izdatel'stvo Moskovskogo universiteta. 376 p.

Tevdoy-Burmuli A.I. (2018) Jetnopoliticheskaja dinamika Evropejskogo sojuza. M.: Aspekt-Press. 224 p.

Veretevskaja A.V. (2018) Mul'tikul'turalizm, kotorogo ne bylo: analiz evropejskih praktik politicheskoj integracii jetnokul'turnyh men'shinstv. M.: MGIMO MID Rossii. 182 p.

\section{Ethnopolitical Dynamics of Europe Revisited}

Author: Oskolkov P., junior research assistant, Department of European Integration Studies, Institute of Europe RAS; lecturer, Department of Comparative Politics, MGIMO University; senior lecturer, Department of Regional Problems of World Politics, Lomonosov Moscow State University. Address: 11-3, Mokhovaya str., Moscow, Russia, 125009. E-mail: p.oskolkov@inno.mgimo.ru

Abstract. Ethnopolitical Studies is one of the most dynamically developing fields of political science, its importance and necessity for world development is hard to overestimate. The Russian tradition of ethnopolitical studies is well developed and widely recognized despite its young age. A new seminal work in this area has just appeared. The article is dedicated to the book "Ethnopolitical Dynamics of European Union" written by Alexander Tevdoy-Burmuli (published by Aspect Press in 2018). This is a textbook of the enlarged group of study fields 41.00.00 "Political Science and Regional Studies". It consists of a theoretical chapter and a few parts structured according to spatial (Western Europe, Central and Eastern Europe) and scope (sub-national, national and supra-national nationalisms) principles. Largely this is a constructivist work; the author presents his views on ethnopolitical interactions in Europe, using a number of original explanatory and analytical theories. He also dwells on the peculiarities of ethnopolitical governance and subject-object relations in the ethnic field. The author places his work in the broader context of global ethnopolitical studies, referring to recent research conducted by leading European and American analysts. In the situation of present "conceptual quagmire" in the field of ethnopolitical studies, according to academician Valery Tishkov, the publication of this book is of significant importance for expert and educational community.

Keywords: Ethnopolitical Studies, ethnopolitical dynamics, ethnopolitics, nationalism, constructivism, European Union, multiculturalism.

DOI: http://dx.doi.org/10.15211/soveurope62018152158 